\title{
OS PRIMEIROS ANOS DA "ESCOLA DE FRANKFURT" NO BRASIL
}

Sílvio Camargo

Para os pesquisadores em ciências sociais se tornou comum o entendimento de que a expressão "Escola de Frankfurt" é uma imprecisão conceitual ${ }^{1}$. Por outro lado, a sua utilização pode servir como forma de exposição acerca da chamada teoria crítica da sociedade, em geral associada ao seu momento inaugural com Max Horkheimer e a fundação do Instituto de Investigação Social de Frankfurt, cujas contribuições para o pensamento contemporâneo são hoje inegáveis.

A teoria crítica se constituiu no século XX como um "modelo" de compreensão da realidade que ultrapassou suas iniciais tonalidades frankfurtianas, e mesmo quanto a estas, formou diferentes gerações, afinal, concordando ou não com suas ideias, poucos questionam a importância de pensadores como Jürgen Habermas e Axel Honneth para a teoria social contemporânea.

Pretendemos neste ensaio indicar alguns aspectos que caracterizam o processo de recepção da teoria crítica da

\footnotetext{
${ }^{1}$ Para maior entendimento do que pensa este autor sobre o tema, ver Camargo (2006a, 2006b).
} 
Escola de Frankfurt no Brasil, no que consideramos ser sua primeira fase: o período de 1968 a 1978. A ênfase recairá sobre a tentativa de apreensão do papel de alguns intelectuais brasileiros que protagonizaram esse processo em diferentes nuances. Intelectuais com formações diferenciadas, posições teóricas distintas, que confluem para a formação de um cenário histórico em que o conjunto de ideias de uma das mais expressivas correntes da teoria social contemporânea aportou no Brasil, foi passível não só de divulgação, como de interpretação, e, após quase meio século, se consolidou nas ciências humanas do país como contribuição imprescindível ao cenário científico e intelectual brasileiro.

Acreditamos não existir, até o presente momento, estudos sistemáticos sobre essa fase do processo, embora se encontrem alguns trabalhos dispersos a respeito ${ }^{2}$, de modo que este artigo pretende contribuir para a elucidação da maneira pela qual a chamada Escola de Frankfurt foi se 106 consolidando principalmente nas ciências sociais do país, possuindo hoje um número considerável de estudiosos, pesquisadores e intérpretes.

Não obstante em diversos momentos, ao longo desses mais de quarenta anos, tenham-se feito referências ao pensamento frankfurtiano como representativo de algum tipo de moda intelectual, sua consolidação nas ciências sociais do país tem mostrado um caminho diferente. Em uma ambientação intelectual em que as questões do subdesenvolvimento e da periferia têm se mostrado renovadamente relevantes para os nossos pensadores, o processo de recepção sobre o qual vamos falar diz respeito não apenas a uma história das ideias, mas também ao modo pelo qual o legado da teoria crítica foi igualmente apropriado, de modos diversos, para pensar tal contexto.

\footnotetext{
2 Informações sobre esse período encontram-se nos seguintes autores: Coutinho (1986); Freitag (1992); Pressler (2006); Chacon (1977, 1994); Soares (2010); Maar (2005); Silva (2007); e Duarte (2009).
} 
A teoria crítica da Escola de Frankfurt teve sua inserção no Brasil a partir de meados da década de 1960, consolidando-se no final da década com as primeiras traduções de obras de pensadores frankfurtianos, inicialmente alguns textos de Walter Benjamin e depois Herbert Marcuse e Theodor Adorno. É possível afirmarmos que dois campos do conhecimento expressaram fortemente o impacto inicial do pensamento frankfurtiano: o dos estudos literários e da comunicação. As primeiras referências ao pensamento frankfurtiano ocorrem a partir de debates quanto à relação entre arte e sociedade durante os anos 1960. É importante lembrarmos que, já nos anos 1950, os autores frankfurtianos eram minimamente conhecidos nacionalmente; Chacon (1994, p. 454), por exemplo, afirma ter mencionado publicamente Theodor Adorno pela primeira vez em 1955.

Em 1965, menos de um ano após o golpe militar no Brasil, Roberto Schwarz fará uso de conceitos centrais benjaminianos na coletânea de ensaios A sereia e o desconfiado, no mesmo ano em que José Guilherme Merquior menciona Benjamin em Razão do poema, livro com orelha de Leandro Konder, outro que começava a se envolver nesse período com o pensamento de Walter Benjamin (cf. Konder, 1967). Os temas em questão se referiam a um texto do autor alemão traduzido pela primeira vez no Brasil em 1968: "A obra de arte na era de sua reprodutibilidade técnica”. Se uma nova geração de críticos literários começa a fazer menções a Benjamin ou a Adorno, por outro lado, não havia, em meados da década de 1960, qualquer entendimento explícito sobre a ideia de teoria crítica ou mesmo sobre a noção de Escola de Frankfurt.

A despeito de a vinculação entre o nome de Benjamin e a Escola de Frankfurt ser conhecidamente polêmica, entendemos que as questões que permeiam a ideia de teoria crítica, em especial no Brasil, estão diretamente associadas ao seu nome até hoje - e entre 1968 e o final dos anos 1970 
parece ser o autor mais debatido por intelectuais do país entre os representantes da teoria crítica. Enquanto que o texto "A obra de arte na era de sua reprodutibilidade técnica" demarca a apreensão inicial dos conceitos de aura, alegoria e mimese, centrais em toda a obra benjaminiana, suas reflexões sobre a modernidade encontram eco entre nossos cientistas sociais e filósofos já na metade dos anos 1970, quando começa a tomar forma, principalmente na Europa, o longo debate entre modernos e pós-modernos. Em 1975, foi publicado o livro $O$ moderno e os modernos, que incluía um dos importantes ensaios sobre Baudelaire, mais tarde reeditado nas Obras escolhidas.

Na passagem aos anos 1970, os debates sobre a comunicação de massas se tornaram mais intensos na academia brasileira e mesmo fora dela, em um contexto em que já há algum tempo eram intensamente debatidas questões sobre cultura nacional e quanto ao próprio conceito de cultura. 108 Se, desde os anos 1940, questões sobre brasilidade e identidade nacional, a busca por uma legítima cultura brasileira, ocupavam o centro de debates intelectuais no país, os anos 1960, antes e depois do golpe militar de 1964, trouxeram ao centro das preocupações de artistas, escritores e cientistas sociais debates sobre cultura, que Marcelo Ridenti (2000), em consonância com ideias desenvolvidas por Michael Löwy, chamou de romantismo revolucionário.

Não por acaso, as primeiras leituras de Benjamin se associavam também ao vínculo deste com o teatro de Brecht, o dramaturgo alemão que dispunha então de uma ampla gama de seguidores e que refletia a ideia de que a cultura deve ter um telos transformador, engajado, revolucionário. Se, por um lado, Benjamin pôde inicialmente estar associado ao campo marxista do pensar a arte, no sentido de uma arte engajada que demarcava também os mecanismos de resistência ao autoritarismo, por outro lado ele introduziu os problemas acerca da relação entre arte e 
técnica, algo ainda pouco debatido nas discussões nacionais sobre cultura. A introdução desse debate, quase inexistente até meados dos anos 1960, ocorre no mesmo momento histórico de consolidação de uma indústria cultural no país, conforme a publicação bastante conhecida de Renato Ortiz (1988): A moderna tradição brasileira.

Nesse contexto, também passaram a figurar no cenário cultural nacional, e de modos distintos, Herbert Marcuse e Theodor Adorno. Este último passou a ter, conforme o nosso entendimento, até os dias de hoje, seu nome sempre associado ao conceito de indústria cultural, embora seu pensamento tenha também se consolidado, já a partir dos primeiros anos da década de 1970, como um contraponto a algumas das teses defendidas por Benjamin sobre a relação entre arte, técnica e sociedade.

Apesar de algumas referências a Benjamin já fossem encontradas antes de 1968, por exemplo em Merquior (1965), Schwarz (1965) e Konder (1967), e somente a partir de um conjunto de traduções de textos dos pensadores frankfurtianos publicadas na Revista Civilização Brasileira que temos maior divulgação das questões da Escola de Frankfurt $^{3}$. O papel dessa revista, publicada entre 1965 e 1968, foi fundamental como órgão de reflexão de intelectuais de esquerda no período, se constituindo, conforme depoimento de Konder (apud Soares, 1999, p. 89), no principal veículo de publicação de intelectuais de esquerda naquele momento. O papel histórico dessa revista na divulgação das ideias de Benjamin, Marcuse e Adorno foi tão importante que representou um marco no processo de recepção do pensamento frankfurtiano no Brasil.

\footnotetext{
${ }^{3} \mathrm{Na}$ Revista Civilização Brasileira, encontramos dois artigos de Marcuse: "Liberdade e agressão na sociedade tecnológica" ( $n^{\circ} 18$, mar./abr. 1968) e "Finalidades, formas e perspectivas da oposição estudantil nos Estados Unidos" (nº 21, set./dez. 1968). De Adorno: "Moda sem tempo: jazz" (n 18, mar./abr. 1968). De Benjamin: "A obra de arte na era de sua reprodutibilidade técnica" (n 19/20, maio/ago. 1968).
} 
No terreno das traduções, já em 1967 surge $A$ ideologia da sociedade industrial (o homem unidimensional) e, em 1968, dois outros livros de Marcuse, Eros e civilização e Materialismo histórico e existência, abrindo uma sequência de traduções do autor que teve até 1973 seis obras publicadas por editoras brasileiras. Nesse mesmo ano, outra editora, a Tempo Brasileiro, que veio a ter um papel igualmente decisivo na divulgação do pensamento frankfurtiano no Brasil, publica um dos primeiros textos de Sérgio Paulo Rouanet sobre a Escola de Frankfurt: o ensaio "De Eros a Sísifo", que sai na edição 17/18 da Revista Tempo Brasileiro. Contudo, Rouanet só se tornará efetivamente um emérito protagonista do processo de recepção da teoria crítica no Brasil a partir do final da década de 1970.

\section{De Merquior a Marcuse}

Foi também a editora Tempo Brasileiro que, em 1969, publi110 cou o livro pioneiro na inserção da Escola de Frankfurt no país, a obra Arte e sociedade em Marcuse, Adorno e Benjamin, de José Guilherme Merquior, que, além de propiciar algumas importantes interfaces entre teoria crítica e psicanálise, fez refletir em seus escritos a influência mundial que tinha Marcuse naquele momento histórico. $\mathrm{O}$ pioneirismo da obra de Merquior deve ser compreendido como algo que demarca a própria literatura internacional sobre teoria crítica, embora redigido originalmente em português. Basta lembrarmos que somente em 1973 é que surgiu a renomada obra histórica de Martin Jay (1986 [1973]) sobre a Escola de Frankfurt.

A obra de Merquior, cuja trajetória intelectual está longe de podermos identificá-lo como um seguidor da teoria crítica, e muito menos do marxismo, traz à tona um olhar acerca dos pensadores frankfurtianos que em parte reflete as mesmas críticas que tais pensadores viriam a receber em âmbito internacional. Ao mesmo tempo, abre certo olhar, principalmente sobre Marcuse e Adorno, que tem uma 
repercussão duradoura na intelligentsia nacional. Merquior retoma a distinção adorniana entre alta cultura e cultura de massas, não se opondo à defesa que faz Adorno da obra de arte autônoma, mas, ao mesmo tempo, critica o que chama de "pensamento negativo" do teórico frankfurtiano, que, ao não ter apresentado formulações políticas transformadoras, o teria conduzido ao que mais tarde Habermas chamará de um "beco sem saída".

Se o mérito de Merquior esteve em ser pioneiro na recepção e divulgação da teoria crítica no Brasil, a parcialidade de sua interpretação, principalmente quanto a Adorno, demonstra uma leitura no mínimo apressada do pensador frankfurtiano. O livro de Merquior se divide em três partes: na primeira, ele aborda Marcuse e Adorno; na segunda, Walter Benjamin; e, em uma terceira parte, as possíveis respostas da ontologia heideggeriana aos impasses frankfurtianos. Embora desconhecesse a ainda não publicada Teoria estética, de Adorno, acusa este de conceber a possibilidade da obra de arte autônoma no sentido de uma promessa de felicidade perdida, e, portanto, destinada à impossibilidade da utopia (Merquior, 1969, p. 56). Da mesma forma, a crítica que fazia Marcuse da sociedade industrial teria conduzido este a algo não além do que a postulação da conhecida "grande recusa". Marcuse e Adorno são interpretados como prisioneiros de um impassível pessimismo, o que se confirma em um trecho da terceira parte do livro.

O utopismo "pedagógico" schilleriano, de Marcuse, e a amargura autofágica da estética de Adorno são repassados da consciência da preguiça da práxis, do senso de ausência de um horizonte revolucionário. Todo messianismo é iminentista. Como a revolução não se apressa, o traço messiânico se transforma em pessimismo agudo. Em todo caso, o apagamento do messianismo não se verifica só no marxismo de Frankfurt (Merquior, 1969, pp. 255-56). 
Mesmo que, na segunda parte do livro, suas posições sejam mais amenas quanto a Benjamin, havendo uma aproximação a este que irá perdurar por muitos anos depois, Merquior, antes de sua imersão no estruturalismo, se mostra ainda muito vinculado a Heidegger, e, como diz Duarte (2009), sem conseguir justificar, entre outras coisas, sequer a relação daquele com o nazismo. Algumas das ideias de Merquior sobre a Escola de Frankfurt foram compartilhadas por muitos intelectuais nas décadas seguintes, curiosamente trazendo certa similaridade com a crítica habermasiana de Adorno e Horkheimer que, naquele momento histórico, ainda era desconhecida mesmo do público alemão.

Aliás, foi igualmente a editora Tempo Brasileiro que publicou a primeira tradução de um texto de Habermas em 1970, na coletânea Humanismo e comunicação de massa, organizada por Vamireh Chacon. Embora Habermas, ao final dos anos 1960, já houvesse publicado alguns textos que foram 112 marco inicial de sua guinada na teoria crítica, até então sua obra mais conhecida, Mudança estrutural na esfera pública, não o alçava ainda à posição de um pensador de renome mundial. E mesmo que seu pensamento já fosse conhecido no Brasil, como vemos nos trabalhos iniciais de Gabriel Cohn (1968a, 1971, 1973), naquele momento as questões que balizavam suas ideias sobre a esfera pública ainda estavam distantes de serem assimiladas, na medida em que vivíamos um contexto em que intelectuais eram exilados, o AI-5 impunha o silêncio ${ }^{4}$, e resquícios do romantismo revolucionário ainda predominavam entre os pensadores de esquerda.

Ao final da década de 1960, Marcuse fazia grande sucesso em todo o mundo, frequentando até mesmo os meios de comunicação (Soares, 2010), enquanto Adorno se ocupava de problemas sociológicos e com a finalização

\footnotetext{
${ }^{4}$ Ato Institucional $\mathrm{n}^{\circ} 5$ : instrumento do governo militar que restringia duramente as liberdades políticas e civis. $\mathrm{O}$ ato foi redigido durante o governo de Artur da Costa e Silva em 13 de dezembro de 1968.
} 
de sua Teoria estética, antes de falecer em $1969^{5}$. Instigante quanto à história de nossas ciências sociais é o pouco conhecimento existente no Brasil na época acerca da controvérsia entre Adorno e Popper, que marca fortemente a teoria sociológica nos anos 1960, e que, de algum modo, quanto à perspectiva de Adorno, contrastava com a forte tendência existente na sociologia brasileira em privilegiar a pesquisa empírica como marco distintivo na busca de consolidação da sociologia como disciplina científica.

Percebemos uma tendência em considerar que o período inicial da recepção da teoria crítica de Frankfurt coincide com os acontecimentos de 1968 (Coutinho, 1986; Soares, 2010), marcado pela tradução de alguns textos de Marcuse que se tornava, naquele momento, uma referência nem sempre bem interpretada para o movimento estudantil, e depois, de forma ainda mais incongruente, pelos divulgadores da contracultura. Como observa Paulo Eduardo Arantes (2004, p. 150), tanto entre professores já renomados como entre estudantes, a recepção de um pensador que repentinamente tornara-se $p o p$ trazia equívocos de leitura que se prolongaram nas décadas seguintes.

Passadas mais de quatro décadas daquele contato inicial com Benjamin, ainda hoje predomina a ideia de que este era o mais marxista dos frankfurtianos, e, em alguma medida, por isso, certa reverência que ele passou a dispor por parte de intelectuais de esquerda, cuja inegável predileção por Gramsci ou Lukács remonta aos distantes anos 1960. As afinidades com Benjamin, contudo, desde então se mostraram como algo bem mais próprio aos intelectuais envolvidos com a crítica literária e a estética do que com os sociólogos, para os quais Benjamin talvez seja filósofo em

\footnotetext{
${ }^{5}$ O pequeno, mas nada simples, texto de Adorno "Capitalismo tardio ou sociedade industrial?" havia sido uma conferência durante o $16^{\circ}$ Congresso de Sociólogos Alemães em 1968. Inúmeros outros textos de Adorno sobre temáticas sociológicas datam da década de 1960.
} 
demasia, embora uma parte central da constelação teórica benjaminiana sempre tenha sido a mesma que a de Adorno e Marcuse: a crítica do fetichismo da mercadoria e da exacerbação contemporânea do valor de troca.

Peculiar quanto à recepção da teoria crítica no Brasil é que os intelectuais que sorvem a letra, sempre complexa, dos frankfurtianos, não são apenas os marxistas, e também não pertencem apenas ao campo acadêmico, como mostra o próprio exemplo de Merquior. Podemos afirmar, mais do que isso, que alguns dos primeiros divulgadores e intérpretes frankfurtianos não são "frankfurtianos", no sentido de intelectuais articulados em torno de uma visão de mundo impressa pela "ideia original de teoria crítica", para lembrarmos o programa inaugural de Max Horkheimer (1983 [1937]). Ao mesmo tempo, principalmente nos anos 1970, houve uma clara aproximação de Schwarz e Cohn aos fundamentos da teoria crítica, mas não acreditamos ser esse o

114 caso de outros importantes expoentes desse mesmo processo histórico, como Konder, Coutinho, Chacon e, principalmente, Merquior.

Logo no início da década de 1970, viu-se arrefecer aquela quase festiva recepção inicial da obra de Marcuse, passando a ficar visível algum interesse pelas obras de outros representantes da teoria crítica, inclusive de seu representante da chamada segunda geração, Jürgen Habermas. Mas a importância deste surgirá bem mais tarde, sobretudo ao longo da década de 1980. Naquele início dos anos 1970, surgem as primeiras traduções de livros de Adorno, assim como alguns capítulos de livros, como nas coletâneas de Costa Lima (1969) e Cohn (1971).

Diferentes fatores contribuíram para que esse período, ainda que breve, tenha sido propício para o amadurecimento do interesse pelos temas da cultura de massas e da indústria cultural. Naquele momento, se consolidava no país uma indústria das comunicações nos moldes criticados pelos 
frankfurtianos, isto é, a consolidação tanto de um aparato publicitário formado em padrões administrativos, como de uma indústria editorial, televisiva, fonográfica e de cinema que não era perceptível no país em décadas anteriores (cf. Ortiz, 1988). Surgiram, desse modo, os primeiros trabalhos nos campos da sociologia da cultura e da sociologia da comunicação, tomando como referência ideias de Adorno e Horkheimer.

É possível dizermos que se Marcuse foi interpretado por boa parte dos intelectuais brasileiros como pensador que de alguma forma inspirava os movimentos da contracultura, ou mesmo de certo irracionalismo, essa interpretação foi expressão de leituras e debates que se deram mais em cafés e outros ambientes externos às discussões acadêmicas. Esfera acadêmica esta na qual o autor de Razão e revolução jamais chegou a se consolidar. E quando esta existiu, esteve mais presente entre os filósofos, que, nos anos 1960, estavam também influenciados pela fenomenologia, o que permitia ver em Marcuse um pensador não identificado ao marxismo tradicional, mas portador de uma abertura que incluía, além disso, a sua releitura de Freud e da psicanálise.

Em Humanismo e comunicação de massa, Chacon (1970, p. 14) reintera algumas percepções sobre teoria crítica, já presentes em Merquior, manifestando uma interpretação, principalmente de Adorno e Horkheimer, comum entre muitos intelectuais brasileiros.

Frankfurt, por sinal, já aparecera despertando polêmicas quanto à sua filiação: uns chamando-a de marxista, outros de neo-hegeliana de esquerda, ou ambas as coisas, paradoxalmente, ao mesmo tempo. Na realidade a melhor catalogação, apesar de todos os perigos, continua a de Hegelianismo quase anárquico, mais descendentes de Schopenhauer e Nietzsche que dos jovens hegelianos, atacados por Marx n’A Sagrada Família. 
Embora Nietzsche tenha sido um filósofo nada desprezível para Adorno, e Schopenhauer tenha tido grande influência em Horkheimer, logo percebemos a grande dificuldade em compreender-se a relação entre teoria crítica e dialética. Como veremos adiante, essa aproximação da crítica frankfurtiana da razão com o irracionalismo, em mais de um momento, impulsionou a leitura brasileira desses autores, que, somente na década de 1980, com a influência de Habermas, terão ainda mais elementos para essa forma, em nosso entendimento bastante questionável, de interpretação.

\section{Cohn: um cavaleiro solitário}

A ideia de uma teoria crítica como expressão de determinada forma de pensar a ciência e a sociedade também não foi o viés através do qual Theodor Adorno passou a ser lido e conhecido no Brasil a partir da década de 1970, apesar das leituras e interpretações pioneiras de Gabriel Cohn

116 no campo da sociologia da comunicação. Para os pesquisadores em Ciências Sociais, Adorno desde o início, assim como Horkheimer, esteve associado ao conceito de indústria cultural, apreensão que acabou predominado nas décadas seguintes. Apesar da atualidade paradoxal do conceito de indústria cultural, que, ao menos no campo sociológico, se tornou uma referência central ao falarmos de Escola de Frankfurt, a "indústria cultural" passou a ser um tema isolado de reflexão quanto aos temas sociológicos presentes na obra de Adorno.

Gabriel Cohn (1971), antes de publicar a coletânea Comunicação e indústria cultural, havia sido tachado por Florestan Fernandes como demasiado apegado aos preceitos weberianos em sua dissertação sobre o petróleo ${ }^{6}$, que, apesar de pouco condizente com o efetivo ideário teórico do

\footnotetext{
${ }^{6}$ Acerca da declaração de Florestan, ver entrevista de Gabriel Cohn em Bastos et. al. (2006, p. 116).
} 
sociólogo, já dizia algo de um jovem pensador que não se situava exatamente no campo dos renomados intelectuais marxistas, então representados por nomes como Caio Prado Júnior, Leandro Konder, Carlos Nelson Coutinho ou mesmo os herdeiros do Seminário de Marx. E não podemos desconsiderar, como diz Paulo Eduardo Arantes (1989), a importância que veio a ter o pensamento marxiano no debate acadêmico entre as décadas de 1960 e 1970, muito embora, como diz Schwarz (1999, p. 103), mediante interpretações que corriam ao largo de entrever o efetivo significado do "fetichismo da mercadoria" como aspecto central para a compreensão das transformações pelas quais passava a nação.

Um pouco antes do livro organizado por Cohn, Luiz Costa Lima (1969) dava início aos estudos em sociologia da comunicação com seu pioneiro Teoria da cultura de massa, onde aparecem ensaios de Adorno, Horkheimer, Marcuse e Benjamin, ao lado de pensadores canônicos do estudo da cultura de massas. Essa obra, que em 2005 já se encontrava na sétima edição, traz uma das traduções feitas no período do texto "A indústria cultural", o debatido "A obra de arte", de Benjamin, e "A arte na sociedade unidimensional", de Marcuse.

No mesmo ano em que defendeu sua dissertação sobre Petróleo e nacionalismo no Brasil, Gabriel Cohn (1968b) começava a mostrar uma nova fisionomia na teoria social brasileira. Na contramão de uma visão corrente de que, no contexto periférico, a sociologia deve privilegiar a compreensão desse próprio contexto, relegando a elaboração teórica aos expoentes dos países centrais, Cohn inicia uma rica, e ainda viva trajetória, de consolidação da teoria social no Brasil. Em 1968, publica também, na Revista Civilização Brasileira, o artigo "A sociologia e a arte da controvérsia" (Cohn, 1968a), no qual, mesmo sem ainda evidenciar a influência frankfurtiana em seu pensamento, já aponta posturas ousadas ao lidar com os problemas da relação entre teoria e empiria, 
manifestando, tal como insistiu Adorno ao longo de toda a década de 1960, a impossibilidade da emancipação sem a existência do rigor teórico.

Na coletânea de 1971, além de dois textos de sua própria autoria, Cohn traz a tradução de um texto de Habermas, e dois ensaios de Adorno, um dos quais o clássico "A indústria cultural", que já havia aparecido no volume organizado por Costa Lima (1969). Na coletânea de Cohn, já se antecipavam alguns dos temas que surgirão em 1973, em Sociologia da comunicação, obra de rara feitura na teoria social brasileira. Os temas são a contraposição, então em voga, entre massa e elite, a diferenciação entre sociedade de massa e cultura de massa, o público e a mensagem, a posição, enfim, da comunicação quanto ao seu estatuto na relação entre produção e consumo.

As duas obras são consideradas pioneiras na então nascente sociologia da comunicação, cuja história, desde 118 então, mostrou tratar-se de uma disciplina de difícil consolidação no campo das ciências sociais (cf. Dias, 2008). Assim como outros grandes nomes da sociologia brasileira, Cohn, desde seus primeiros trabalhos, insiste na reflexão sobre a condição da sociologia como ciência, o que não impede que, principalmente em seus textos de maturidade, a forma do ensaio venha a expressar uma maneira própria, e influenciada por Adorno, de pensar a relação entre teoria crítica, sociologia e conhecimento, nem sempre conforme os cânones da tradição sociológica.

Após delinear o conjunto de problemas que caracterizariam uma chamada sociologia da comunicação, Gabriel Cohn (1973) estabelece diálogo com parte considerável dos principais teóricos da sociologia contemporânea, levantando problemas que extrapolam o campo específico da comunicação, e que podem ser mais bem situados como teórico-sociais. Nos dois capítulos finais do livro, ele apresenta, num tom que parece ser até mesmo de alívio, quais são afinal suas 
principais referências sobre o tema da comunicação e, por que não dizer, como ficará claro nas décadas seguintes, de sua própria compreensão teórica da sociedade.

Nesse ponto, chegamos ao final de nossa caminhada neste capítulo, na medida em que se abre a possibilidade de introduzir na discussão aquela linha de pensamento que, segundo a entendemos, representa a síntese de tudo aquilo que há de cientificamente relevante nas proposições examinadas antes, acrescida de elementos próprios da maior importância. Trata-se da perspectiva representada pela chamada "escola de Frankfurt" que se reuniu (até a sua recente dissolução) em torno de Max Horkheimer, e cujo representante máximo, naquilo que concerne ao presente trabalho, é Theodor W. Adorno (Cohn, 1973, p. 124).

Uma década após publicar esse livro, Cohn já se consolidava no cenário intelectual brasileiro como grande intérprete da teoria crítica da sociedade. Suas traduções de textos sociológicos adornianos são até hoje a mais importante referência bibliográfica em português na área ${ }^{7}$. Mas, antes disso, houve Max Weber e a original exposição de Cohn, no final dos anos 1970, sobre o sociólogo alemão (Cohn, 1978). Ao invés de acreditarmos que Cohn esquecera Frankfurt enquanto se dedicara ao denso trabalho sobre Weber, evidencia-se o contrário. Não obstante ele ter afirmando em Sociologia da comunicação (1973, p. 126) que os textos de maturidade de Adorno apreendiam a noção de indústria cultural em um sentido muito mais enfaticamente centrado no fetichismo da mercadoria de Marx do que no tema da racionalização de Weber, será o mesmo Weber quem consolidaria certo modo de lidar com o modelo frankfurtiano.

\footnotetext{
${ }^{7}$ Referimo-nos, por exemplo, à coletânea organizada por Gabriel Cohn, publicada em 1986: Adorno - Sociologia (São Paulo: Ática).
} 
Estamos nos referindo aqui, e concordando em boa medida com a interpretação de José Maurício Domingues (2011), à ideia de que o conceito de dominação se constitui, desde aquela época, na questão central, mas poucas vezes explícita, das formulações sociológicas de Cohn. Não devemos esquecer, aliás, que a dominação é também o grande tema de toda a obra de Adorno (Camargo, 2006b; Honneth, 1991), autor que Gabriel Cohn não esconde ser o seu predileto no amplo espectro da teoria social contemporânea. Em uma época em que poucos ousavam se dedicar fundamentalmente à teoria, aliás, como até hoje, a posição de Cohn parece também ser um pouco singular, não só no campo sociológico, como o comparando com outros expoentes desse período na recepção do pensamento frankfurtiano.

Enquanto José Guilherme Merquior, no início dos anos 1970, assumiu posições políticas mais conservadoras e teoricamente se mostrava cada vez mais próximo do estrutura120 lismo, pensadores como Konder e Coutinho representavam o que podemos chamar de marxismo tradicional, sem qualquer conotação pejorativa ao termo, com incursões significativas no campo filosófico. Com Roberto Schwarz se dedicando à teoria literária, Gabriel Cohn era, naquele momento, uma voz quase solitária na sociologia brasileira. Entendemos que Cohn apreende naquele momento não aquilo que é o mais central na trajetória frankfurtiana, mas, nessa trajetória, o que era mais significativo para aquele processo histórico da realidade brasileira, a compreensão do fenômeno da indústria cultural, até então um tema secundário nos debates nacionais, centralizados nas questões sobre a brasilidade e a identidade nacional.

A evidência de que o problema da indústria cultural, para alguns da cultura de massas, se tornava um tema emergente nas ciências sociais, se expressa na elaboração de algumas teses de mestrado e doutorado que passaram a ser produzidas pelo país, principalmente na Universidade 
de São Paulo, nos primeiros anos da década de 1970. Não obstante essas pesquisas iniciais não evidenciassem em sua feitura a pretensão de uma prática sociológica ancorada, em sentido metodológico e epistemológico, em uma teoria crítica da sociedade, marcaram significativamente a história recente das ciências sociais no país ${ }^{8}$.

Adorno e Horkheimer passam a ter, a partir desse contexto, uma pequena gama de seguidores em campos diversos das ciências humanas, mas praticamente ignorados nos cursos de filosofia, por exemplo, onde a efetiva penetração do pensamento frankfurtiano só foi ocorrer a partir do advento da segunda geração da Escola de Frankfurt, personalizada em Habermas. Apesar disso, outros textos importantes de Adorno e Horkheimer também tiveram tradução para a língua portuguesa, como o importante livro Temas básicos de sociologia, e Notas de literatura I- ambos em 1973; e Filosofia da nova música - em 1974.

Por um lado, percebemos que, nesse período, o pensamento de esquerda e as próprias iniciativas editoriais começaram a demonstrar maior entusiasmo por pensadores como Gramsci e Lukács; por outro lado, não podemos ignorar que pensadores que de algum modo estiveram próximos ao pensamento frankfurtiano também já circulavam em língua portuguesa, como é o caso de Erich Fromm, com incontáveis traduções desde 1960, e o instigante livro de Ernest Bloch sobre Thomas Münzer, publicado em 1974. Além disso, não podemos desconsiderar igualmente que, desde o início dos anos 1960, era possível encontrar uma ou outra versão em espanhol de textos frankfurtianos ou mesmo do original alemão como a Dialética do esclarecimento (Adorno e Horkheimer, 1985 [1947]), conforme

\footnotetext{
${ }^{8}$ Destaque para Sérgio Miceli (1972), com A noite da madrinha, e Maria Arminda do Nascimento Arruda (2004 [1979]), com A embalagem do sistema - ambas publicadas em livro; além das teses de Eclea Bosi; Angeluccia Habert; Othon Barbosa; Orlando Pinto de Miranda, entre várias outras.
} 
depoimento de Roberto Schwarz (2003), sem falarmos de The authoritarian personality (Adorno et al. 1950), mencionado por Chacon (1994), que era uma obra utilizada em cursos de metodologia da Universidade de São Paulo ainda durante a década de 1950.

\section{Entre 0 conceito e a realidade}

Dentre aqueles intelectuais responsáveis pela introdução da Escola de Frankfurt no Brasil, possivelmente Roberto Schwarz tenha sido o que mais enfaticamente, embora não menos sutilmente, se ocupou de temas tipicamente nacionais, iluminando-os com conceitos da teoria crítica. Isso se refere tanto à originalidade com que se consolidou na crítica literária como aos seus textos diretamente relacionados a uma interpretação do país. A presença dos frankfurtianos em seu pensamento já era visível no início dos anos 1960, desde o pioneiro A sereia e o desconfiado (Schwarz, 1965).

122 Naquele momento, o seu interesse pela obra de Adorno já era tão significativo que quase havia ido para Alemanha estudar com o mestre alemão (cf. Almeida, 2007, p. 45).

Schwarz trazia em sua bagagem os ensinamentos de Antonio Candido e a experiência do Seminário de Marx, afora que, em suas formulações, propusesse um "ecletismo" bem distinto daquele de Florestan Fernandes: um ecletismo do campo marxiano, que incluía Lukács, Benjamin, Adorno e Brecht. Assim como no caso de Gabriel Cohn, ousamos afirmar que Adorno teria sido a influência mais perceptível do pensamento de Schwarz. E tanto em um caso como em outro, influência significa a incorporação de uma forma de pensar a sociedade que dispensa as facilidades, os atalhos conceituais e o caminho mais curto no ato de elaboração teórica.

Formado originalmente em ciências sociais, migrando depois para a teoria literária, Schwarz não seria um sociólogo de ofício; aos olhos dos pares da crítica literária, por outro lado, era considerado um crítico demasiado sociólogo. 
Dilema similar ao vivido por Adorno. Mesmo que considerável parte de seus ensaios, distribuídos por vários livros, abordem temas literários, suas interpretações da sociedade brasileira em diferentes momentos históricos trazem uma incontestável contribuição para a sociologia nacional, na medida em que seu posicionamento acerca da relação entre forma literária e processo social o insere claramente na tradição da teoria crítica da sociedade.

Schwarz emite sinais de ter entendido lucidamente o que Adorno chamou de crítica imanente, e tal entendimento se manifestou na forma de uma exposição inquieta do pensamento do autor da Dialética negativa. Mas tal se deu como algo incorporado, seja em suas críticas da literatura ou em seus ensaios de interpretação da realidade nacional. Muito conhecidos são seus textos "Nota sobre vanguarda e conformismo" (de 1967) e "Cultura e política, 1964-1969”, ambos publicados em O pai de família e outros estudos (Schwarz, 1978), em que o autor pensa o papel dos intelectuais em moldes não muito comuns naquele momento histórico.

Já ambientado na rica crítica frankfurtiana da noção de "progresso", consegue apreender no âmbito da música, do cinema, do teatro e da literatura que marcam a passagem dos anos 1960 aos 1970 os traços daquilo que já era claro na Alemanha, e principalmente nos Estados Unidos, há mais de duas décadas, e que viria a ser também no Brasil, isto é, o entrelaçamento entre cultura e mercado, em formatos que se autoconstituíram até mesmo como crítica desse processo: "Vendeu-se, está criticando, ou vendeu-se criticando?" (Schwarz, 1978, p. 48).

Ainda mais polêmico é o ensaio de Schwarz "As ideias fora do lugar", escrito em 1973 e republicado em 1977 no paradigmático Ao vencedor as batatas (Schwarz, 2000), em que a literatura brasileira do século XIX é interpretada como forma estética de elucidação de uma experiência capitalista 
em grande medida singular, ao gosto de muitos, chamada de periférica. Mas tal experiência, para Schwarz, não deixa de ser vista a partir de uma recorrência, mesmo implícita, a seus mestres Lukács e Adorno, com seu conceito de totalidade. $\mathrm{O}$ valor e o trabalho abstrato não estão ausentes do contexto periférico, diga-se, não explicitamente pensado por Adorno, mas assumem peculiaridades que são traços da sociedade brasileira, alguns destes já antes apontados por Sérgio Buarque de Hollanda, e que Schwarz mostra como uma modernidade descompassada. Como diz Miceli (2007, pp. 39-40), sobre a interpretação de Schwarz quanto ao primeiro Machado de Assis:

Ou, por outro lado: no grande realismo a figuração da totalidade da vida concreta dos homens só podia se realizar através da figuração do papel central do dinheiro, o que não vale tal e qual na periferia, onde operam com atualidade formas arcaicas - sobretudo as relações paternalistas. Daí o romance da primeira fase está às voltas com o oxímoro do "obséquio impessoal” que Roberto Schwarz expõe à luz do dia na análise penetrante dos primeiros romances.

A totalidade, assim, se dialetiza negativamente na dualidade. Ao pesquisador brasileiro, que só tardiamente teve acesso à Dialética negativa de Adorno ${ }^{9}$, talvez valha a pena ler com cuidado a original interpretação de Schwarz da obra de Machado de Assis, para ver como uma teoria crítica da sociedade pode ser esclarecedora não só nos rigorosos parâmetros das pesquisas sociológicas empíricas, mas também nas sutilezas da crítica literária. Aqui, a dialética do universal e do particular, a contradição e a recusa da síntese, o

\footnotetext{
${ }^{9}$ Esta, que pode ser considerada a principal obra de Adorno, teve sua primeira tradução em português, publicada no Brasil, em 2009, pela editora Zahar. Aos estudiosos, antes disso, restavam traduções em inglês, espanhol ou a leitura no original em alemão.
} 
não idêntico que se afirma enquanto tal refletiram-se na interpretação de "Helena" ou "Iaiá Garcia" (Schwarz, 2000), como a manifestação de uma dominação capitalista que se expressa na forma de relações patriarcais e paternalistas, que tornam explícitas a realidade escravocrata como constância contraditória na formação da sociedade brasileira.

Não obstante a grande importância de Lukács e Benjamin para Schwarz, entendemos ser Adorno a figura central na forma de crítica por ele empreendida desde meados dos anos 1970. E será também nesse momento histórico que outro importante intelectual surgirá no cenário nacional como responsável pela consolidação das ideias frankfurtianas no país a partir de uma evidenciada predileção pelas ideias de Benjamin. Trata-se de Flávio Kothe. Enquanto Schwarz já incorporava procedimentos da teoria crítica em seus ensaios sobre a realidade nacional, não tendo escrito qualquer estudo sistemático sobre este ou aquele dentre os pensadores de Frankfurt, diferente será o papel cumprido por Kothe. Autor de dois livros que até hoje são referências entre o público brasileiro no estudo de Benjamin, empreendeu uma pesquisa sobre Adorno e Benjamin que, naquele momento, era original não só no Brasil, mas em nível internacional, como o fora antes Merquior, até hoje não suficientemente reconhecida pelos intelectuais do país.

Também vitimado pelas perseguições do regime militar, as contribuições de Kothe, que se consolidaram nas décadas seguintes, foram cruciais para a introdução do pensamento frankfurtiano no Brasil, tanto no âmbito da crítica literária e da filosofia, como da teoria social. Em 1975, ele defendeu a primeira tese de doutorado no país sobre um pensador da Escola de Frankfurt que resultou no livro Benjamin $\mathcal{E}$ Adorno: confrontos (Kothe, 1978). Já em 1976, havia publicado o primeiro livro introdutório sobre Benjamin no Brasil, onde apresenta ao público, de forma clara, as principais ideias do autor de A origem do drama barroco alemão. 
Um dos aspectos da originalidade deste livro de Kothe (1978) está em detalhar as diferenças entre Benjamin e Adorno, sobretudo quanto à compreensão do papel da tecnologia diante da utopia da obra de arte autônoma. Discussão que, se, por um lado, balizava o próprio ambiente de recepção dos frankfurtianos no início dos anos 1970, por outro lado, ainda não havia sido meticulosamente estudado, como se poderia supor, nem mesmo na Alemanha. Flávio Kothe se tornou reconhecido no campo intelectual brasileiro sem deixar de trazer o marco de certo estranhamento e polêmica principalmente quanto a inúmeros de seus pares do campo acadêmico. Habilidoso também com a força e dificuldades da língua alemã, foi responsável por traduções significativas, como de alguns importantes textos de Walter Benjamin.

Sempre atento aos desdobramentos do fetichismo da mercadoria, com destaque para o campo literário, Kothe não deixa barato a quase naturalizada metamorfose da 126 palavra em mercadoria. Ao contrário de Merquior, e não só quanto às orientações ideológicas, sua pesquisa foi inteiramente realizada com fontes primárias, com base em centenas de textos de Benjamin e Adorno, elucidando ao público brasileiro conceitos benjaminianos que só mais tarde se tornariam amplamente debatidos, como mimese, aura, alegoria, experiência. Também diferente de Schwarz e Cohn, a leitura que Kothe fez de Adorno foi bastante dura, com acusações pouco polidas ao autor da Dialética negativa, corroborando, mesmo indiretamente, uma leitura comum da obra de Adorno, não isenta de polêmica, na medida em que outros intérpretes mais tarde tiveram a oportunidade de desmistificar alguns exageros ali apontados sobre as efetivas diferenças entre Benjamin e Adorno (cf. Freitag, 2003).

Assim como no caso de nomes expressivos da sociologia e da filosofia contemporâneas, também os pensadores frankfurtianos, já nesse primeiro período de recepção, foram passíveis de críticas e formas de interpretação que 
se dão à margem de sua leitura ou de uma leitura bastante parcial de suas obras. Na metade dos anos 1970, apenas o texto sobre a indústria cultural havia sido traduzido para o português da mais paradigmática obra da Escola de Frankfurt que é a Dialética do esclarecimento ${ }^{10}$. Na edição da coleção Os Pensadores, da editora Abril Cultural, em 1975, o lapidar excurso sobre o "conceito de iluminismo" foi traduzido por Zelijko e Andéa Loparic, que junto a outros ensaios centrais sobre teoria crítica pode ser visto como outro marco na recepção da Escola de Frankfurt no Brasil. Outros textos importantes, por outro lado, só tiveram traduções na década de 1980, como é o caso dos volumes publicados na coleção Sociologia, da editora Ática.

Se a tese da indústria cultural teve para alguns pensadores o caráter de uma descoberta, afinal iluminava teoricamente o espetáculo incipiente dos meios de comunicação de massa no país, com destaque ao aprimoramento técnico da indústria televisiva, o seu estudo efetivo, principalmente por parte dos intelectuais de esquerda, teve vida curta. Saídos das longas discussões sobre a cultura nacional, embrenhados na necessidade de explicar a natureza da cultura popular, o entendimento sobre a relação entre indústria cultural e racionalidade moderna se tornou em muitos casos em falta de entendimento quanto ao significado da teoria crítica. A partir de uma leitura rápida de Adorno e Horkheimer, se consolidaram os estereótipos acerca do negativismo, do pessimismo, da ausência de um telos programático que invalidaria a crítica frankfurtiana da modernidade.

Mesmo Carlos Nelson Coutinho, um incentivador da divulgação da Escola de Frankfurt no país, expressou no campo das ideias marxistas o que outros nada marxistas, como Merquior e Rouanet, igualmente o fizeram em dife-

\footnotetext{
${ }^{10}$ A primeira tradução do livro em versão integral só aparecerá em 1985 , pela editora Jorge Zahar, em trabalho realizado por Guido A. de Almeida.
} 
rentes momentos, uma grande preocupação em denunciar o irracionalismo, seja como característica de uma prática política insinuante desde o Maio de 1968, seja como ruptura epistemológica, também ceivada de consequências políticas, formuladas a partir de um recrudescimento de Nietzsche no meio intelectual francês. Mais tarde, na década 1980, Rouanet ocupará uma posição de destaque na denúncia do "falso irracionalismo", mas também na consolidação de certa interpretação quanto à primeira geração de frankfurtianos.

A constatação de que Adorno e Horkheimer teriam se afastado da herança racionalista da Aufklärung certamente não foi uma peculiaridade do contexto brasileiro, mas uma leitura predominante na teoria social contemporânea. Mas tal problematização sobre as heranças kantianas no pensamento frankfurtiano serão a marca do segundo período de recepção, que acreditamos se situar entre 1979 e 1994 (Camargo, 2012). Sobre o período histórico de que estamos 128 falando, era visível uma crítica ainda mais evidente, espantosa para os militantes de esquerda, de que o proletariado não seria mais o potencial sujeito de um processo revolucionário. É assim que, paradoxalmente, a ideia mais ou menos evidente e até simpática para os intelectuais críticos ao "status quo" acerca da existência de uma indústria cultural no país passa ao largo de ser estudada de forma mais efetiva. Não havia como negligenciar problemas que eram considerados mais prementes.

Ao mesmo tempo que a luta armada evidenciara a sua fragilidade como forma de resistência ao regime, este dava seus primeiros sinais de abertura, enquanto o movimento sindical aos poucos se rearticulava para emergir como o grande fato político do final dos anos 1970. Diante das manifestações sociais, da eclosão das greves na região do ABC paulista, do retorno de alguns exilados, nada mais estranho do que um discurso teórico, como aquele de Adorno e Horkheimer, acerca da incapacidade histórica do 
proletariado. O que começava a se apresentar como importante era então já não mais a crítica da indústria cultural, uma crítica pouco duradoura, que só ressurgirá com alguma força mais tarde, pois as questões relativas à democracia, à esfera pública e à soberania popular se tornavam centrais.

No campo daqueles que, apesar da urgência histórica, não deixaram de pensar as questões da cultura, no amplo espectro do que podemos chamar de reflexão acerca da obra de arte, a aceitação das ideias de Benjamin parece ter sido menos afeita ao exercício da controvérsia. No período aqui tratado, que vai de 1968 até 1978, exceto Gabriel Cohn, que desde o início expressou uma afinidade eletiva com a teoria da sociedade de Adorno, os demais protagonistas da recepção frankfurtiana no país sempre mantiveram algum grau de aproximação com as ideias de Benjamin. Um estreitamento que implicava também o importante papel de Brecht para os artistas e intelectuais brasileiros, e que, afinal de contas, sempre esteve mais próximo de uma prática cultural portadora, para usar o termo de Ernest Bloch, dotada de esperança.

$* * *$

A recepção da Escola de Frankfurt no Brasil é passível de ser compreendida, conforme nosso entendimento, em três fases distintas (1968-1978; 1979-1993; 1994 até o presente). A primeira fase, sobre a qual falamos neste ensaio, curiosamente se encerra quando foi publicada a primeira tese de doutorado no país sobre Walter Benjamin (Kothe, 1978), fato que, em vez de iniciar um novo momento de apreensão da obra de Benjamin, na verdade simboliza o término de um ciclo no qual ele foi protagonista. $\mathrm{O}$ novo ciclo que se abre, ao final dos anos 1970, coincide com ascensão de Habermas no cenário intelectual mundial, cujos reflexos foram imediatos no contexto intelectual brasileiro, para ficarmos no campo acadêmico, tanto na filosofia como nas ciências sociais. 
Essa constatação nos conduz a uma conclusão preliminar, a de que, se houve algumas especificidades quanto ao modo como os frankfurtianos foram aqui acolhidos, esta não passou por uma radical diferenciação com leituras mais amplas feitas no cenário internacional quanto à teoria crítica e sua história desde os anos 1930. As interpretações predominantes na Alemanha e nos Estados Unidos sobre a Escola de Frankfurt repercutiram aqui, ou se assemelharam, de forma evidente. Por outro lado, o contexto histórico nacional abordado traz pelo menos três peculiaridades que nos ajudam a compreender a recepção da teoria crítica no Brasil. Em primeiro lugar, o contexto do regime militar e o papel dos intelectuais diante dele; em segundo lugar, a modernização dos meios de comunicação, incidindo na consolidação da indústria cultural no país; em terceiro lugar, os dilemas específicos das ciências sociais como área do saber que só então consolidava um sistema nacional de pós-graduação e de pesquisa.

130 É claro que, ao enfatizarmos aqui o papel de alguns intelectuais, deixamos de fora outros tantos, de campos diversos do conhecimento, e também uma multiplicidade de acontecimentos, como a repercussão do pensamento frankfurtiano em diferentes tipos de publicações, como jornais e revistas, e o estudo das obras de Adorno, Horkheimer, Marcuse e depois de Habermas em cursos de graduação e pós-graduação espalhados pelo país. Nesse sentido, nosso pequeno artigo pretendeu também abrir caminho para que outros pesquisadores interessados pelo tema explorem esses outros aspectos do processo de recepção.

Em outro texto (cf. Camargo, 2012), tivemos a oportunidade de falar um pouco sobre as outras duas fases da Escola de Frankfurt no Brasil, mas não há como negligenciar que alguns aspectos daquilo que foi iniciado há pouco mais de quarenta anos continua a repercutir no presente. Não obstante a diversidade bem maior que temos hoje de traduções e publicações de e sobre os frankfurtianos, além 
de teses, eventos, estudos, grupos de pesquisa etc., pelo menos dois dos pensadores aqui comentados continuam a ser, de forma atuante, referências para os estudiosos da teoria crítica. Falo de Roberto Schwarz e de Gabriel Cohn. Ao mesmo tempo, contraditoriamente, a ideia mais conhecida, divulgada e debatida da herança de Adorno e Horkheimer, o conceito de indústria cultural, ocupa hoje uma posição tão marginal quanto em 1968. O conceito de indústria cultural se banalizou tanto que perdeu seu sentido original, sem falarmos que foi sobrepujado por outras visões acerca da cultura, em geral pretensamente mais otimistas. Mas deixemos de lado a crítica da crítica e lembremos apenas como diz Schwarz (2012, p. 50): que, no fim das contas, "Adorno não fez as pazes com o capital”.

\section{Sílvio Camargo}

é professor no Departamento de Sociologia do Instituto de Filosofia e Ciências Humanas (IFCH) da Unicamp.

\section{Bibliografia}

ADORNO, T. W.; HORKHEIMER, M. 1985 [1947]. Dialética do esclarecimento.

Rio de Janeiro: Zahar.

ADORNO, T. W. et al. 1950. The authoritarian personality. New York: Harper and Row.

ALMEIDA, J. 2007. "Pressupostos, salvo engano, dos pressupostos, salvo engano". In: CEVASCO, M. E.; OHATA, M. (orgs.). Um crítico na periferia do capitalismo: reflexões sobre a obra de Roberto Schwarz. São Paulo: Companhia das Letras. pp. 44-53.

ARANTES, P. E. 1989. "Falsa consciência como força produtiva". Lua

Nova, n. 19, nov., pp. 37-46. . 1992. Sentimento da dialética na experiência intelectual brasileira. São

Paulo: Paz e Terra. . 2004. Zero a esquerda. São Paulo: Conrad.

ARRUDA, M. A. N. 2004 [1979]. A embalagem do sistema: a publicidade no capitalismo brasileiro. São Paulo: Edusc.

BASTOS, E. R. et al. 2006. Conversas com sociólogos brasileiros. São Paulo: Ed. 34. pp. 115-34. 
CAmARGO, S. 2006a. "Axel Honneth e o legado da Teoria Crítica". Política Ẽ Trabalho, João Pessoa (PB), n. 24, pp.123-38. . 2006b. Modernidade e dominação: Theodor Adorno e a teoria social contemporânea. São Paulo: Annablume/Fapesp. . 2012. "Itinerários da teoria crítica na sociologia brasileira". In: SILVA, J. P. (org.). Sociologia crítica no Brasil. São Paulo: Annablume. pp. 155-86.

CHACON, V. (org.) 1970. Humanismo e comunicação de massa. Rio de Janeiro: tempo brasileiro. . 1977. História das ideias sociológicas no Brasil. São Paulo: USP/ Grijalbo. . 1994. "A recepção da Escola de Frankfurt no Brasil”. Revista Brasileira de Filosofia, v. XLI, Fac. 176, pp.453-7.

COHN, G. 1968a. "A sociologia e a arte da controvérsia”. Revista Civilização Brasileira, n. 19, maio, pp. 229-50. 1968b. Petróleo e nacionalismo. Corpo e alma do Brasil. São Paulo:

Difusão Europeia do Livro. . (org.) 1971. Comunicação e indústria cultural. São Paulo: Companhia Editora Nacional/Edusp. 1973. Sociologia da comunicação: teoria e ideologia. São Paulo: Pioneira. . 1978. Crítica e resignação. Fundamentos da sociologia de Max Weber.

São Paulo: T. A. Queiroz.

COSTA LIMA, L. (org.) 1969. Teoria da cultura de massa. Rio de Janeiro: Saga. COUTINHO, C. N. 1986. "A Escola de Frankfurt e a cultura brasileira”. Revista Presença, n.7, p.100-12.

DIAS, M. T. 2008. "Sociologia da comunicação no Brasil: apontamentos iniciais para uma necessária pauta de estudos”. In: WAIZBORT, L. (org.). A ousadia crítica: ensaios para Gabriel Cohn. São Paulo: Azougue. pp. 89-98. DOMINGUES, J. M. 2011. "Dominação e indiferença na teoria crítica de Gabriel Cohn”. In: Teoria crítica e (semi)periferia. Belo Horizonte: Ed. UFMG. DUARTE, R. 2009. "Sobre la recepción de la teoría crítica en Brasil: el caso Merquior”. Constelaciones - Revista de Teoria Crítica, n. 1, dec., pp.36-50. FREITAG, B. 1974a. "A sociologia alemã hoje”. Debate e Crítica, São Paulo, v. 2, n. 4, jan./jun. . 1974b. "Habermas e a teoria do conhecimento como teoria social".

Debate e Crítica, n.4, nov., pp.61-82. 1992. "Habermas e a Editora Tempo Brasileiro ou a recepção de Habermas no Brasil”. Revista Tempo Brasileiro, v. 111, pp. 87-108. 2003. "A construção da teoria crítica. Uma troca de cartas entre Adorno e Horkheimer”. Tempo Brasileiro, n. 155, pp. 157-73. 
HONNETH, A. 1991. The critique of power. Reflective stages in a critical social theory. London: The MIT Press.

HORKHEIMER, M. 1983 [1937]. Teoria tradicional e teoria crítica. São Paulo: Abril Cultural. pp. 117-54.

JAY, M. 1986 [1973]. La imaginación dialéctica. Madrid: Taurus.

KONDER, L. 1967. Os marxistas e a arte. Rio de Janeiro: Civilização Brasileira.

KOTHE, F. 1976. Para ler Benjamin. Rio de Janeiro. Francisco Alves. 1978. Benjamin Ẽ Adorno: confrontos. São Paulo: Ática.

MAAR, W. L. 2005. "Notas sobre la teoría crítica em Brasil”. Revista

Internacional de Filosofia Política, Barcelona, n.26, pp.45-51.

MERQUIOR, J. G. 1965. Razão do poema. Rio de Janeiro: Civilização Brasileira. . 1969. Arte e sociedade em Marcuse, Adorno e Benjamin. Rio de Janeiro:

Tempo Brasileiro.

MICELI, S. 1972. A noite da madrinha. São Paulo: Perspectiva. . 2007. "O chão e as nuvens: ensaios de Roberto Schwarz entre arte e ciência”. In: CEVASCO, M. E.; OHATA, M. (orgs.). Um crítico na periferia do capitalismo: reflexões sobre a obra de Roberto Schwarz. São Paulo: Companhia das Letras.

ORTIZ, R. 1988. A moderna tradição brasileira. São Paulo: Brasiliense.

PRESSLER, G. 2006. Benjamin, Brasil: a recepção de Walter Benjamin, de 1960 a 2005 - um estudo sobre a formação da intelectualidade brasileira.

São Paulo: Annablume.

RIDENTI, M. 2000. Em busca do povo brasileiro: artistas da revolução, do CPC à era da TV. Rio de Janeiro: Record.

ROUANET, S. P. 1968. "De Eros a Sísifo". Revista Tempo Brasileiro, n. 17/18. SCHWARZ, R. 1965. A sereia e o desconfiado. Rio de Janeiro: Civilização Brasileira. 1978. O pai de família e outros estudos. Rio de Janeiro: Paz e Terra. 1999. Sequências brasileiras. São Paulo: Companhia das Letras. 2000. Ao vencedor as batatas. São Paulo: Ed. 34 2001. Um mestre na periferia do capitalismo. São Paulo: Ed. 34. 2003. Entrevista. Revista Cult, ano VI, n. 72, pp. 8-12. . 2006. Que horas são? São Paulo: Companhia das Letras. 2012. Martinha versus Lucrécia. São Paulo: Companhia das Letras.

SILVA, J. P. 2007. Teoria crítica e sua recepção no Brasil. Idéias, v. 14, pp. $137-47$.

SOARES, J. C. 1999. Marcuse no Brasil. Londrina: Cefil. . 2010. A recepção das ideias de Marcuse no Brasil. Disponível em: <http://www.uta.edu/huma/illuminations/marc1.htm>. Acesso em: 25 set. 2010. 


\section{OS PRIMEIROS ANOS DA “ESCOLA DE FRANKFURT” NO BRASIL}

\section{SÍLVIO CAMARGO}

Resumo: Nosso objetivo neste artigo é mostrar o que consideramos ser a primeira fase do processo de recepção da Escola de Frankfurt no Brasil, com ênfase na produção de alguns intelectuais brasileiros, pioneiros nesse processo não apenas como tradutores e divulgadores da teoria crítica, mas também como intérpretes da realidade nacional. Esse período histórico foi marcado ao mesmo tempo pela repressão do regime militar, pela consolidação da indústria cultural e pelo crescimento das ciências sociais no país. Apontamos para a importância de intelectuais como José G. Merquior, Roberto Schwarz, Gabriel Cohn e Flávio Kothe, que, em diferenciadas nuances teóricas, iniciaram a recepção das ideias frankfurtianas no Brasil e sua imersão em nosso contexto intelectual. Apontamos ainda as dificuldades de compreensão de um modelo de pensamento bastante complexo.

Palavras-chave: Escola de Frankfurt; Intelectuais brasileiros; Cultura; Ciências Sociais.

\section{THE FIRST YEARS OF THE FRANKFURT SCHOOL IN BRAZIL}

Abstract: Our purpose in this article is to show what we consider to be the first phase of the reception of the Frankfurt School in Brazil with emphasis on the production of some Brazilian scholars who were the pioneers in this process, not only as translators and publishers of the critical theory, but also as interpreters of the national reality. This period of history, was marked by the repression of the military regime, by the consolidation of the culture industry and at the same time the increase of the Social Sciences in the country. We point out the importance of scholars 
such as José Guilherme Merquior, Roberto Schwarz, Gabriel Cohn and Flávio Kothe, who in different theoretical nuances began to receive frankfurter ideas in Brazil and began its immersion in our intellectual context. We also point out yet the difficulties in understanding a very complex thought model.

Keywords: Frankfurt School; Brazilian Scholars; Culture; Social Sciences. 